\title{
Measuring quality of care: A review of previously used methodologies and indicators
}

Katherine Tumlinson

Follow this and additional works at: https://knowledgecommons.popcouncil.org/departments_sbsr-rh

Part of the Demography, Population, and Ecology Commons, Family, Life Course, and Society Commons, International Public Health Commons, Maternal and Child Health Commons, and the Women's Health Commons How does access to this work benefit you? Let us know!

\section{Recommended Citation}

Tumlinson, Katherine. 2016. "Measuring quality of care: A review of previously used methodologies and indicators," Working Paper 2 of the Measuring and Monitoring Quality of Services and Quality of Care Project. New York: Population Council. 


\section{MEASURING QUALITY OF CARE: A REVIEW OF PREVIOUSLY USED METHODOLOGIES AND INDICATORS}

Katherine Tumlinson 


\section{Popuration \\ Ideas. Evidence. Impact.}

The Population Council confronts critical health and development issues-from stopping the spread of HIV to improving reproductive health and ensuring that young people lead full and productive lives. Through biomedical, social science, and public health research in 50 countries, we work with our partners to deliver solutions that lead to more effective policies, programs, and technologies that improve lives around the world. Established in 1952 and headquartered in New York, the Council is a non-governmental, non-profit organization governed by an international board of trustees.

Population Council

One Dag Hammarskjold Plaza

New York, New York 10017

\section{popcouncil.org}

Suggested citation: Tumlinson, Katherine. 2016. "Measuring Quality of Care: A Review of Previously Used Methodologies and Indicators." Working Paper Two of the Measuring and Monitoring Quality of Services and Quality of Care Project. New York: Population Council. 


\section{Table of Contents}

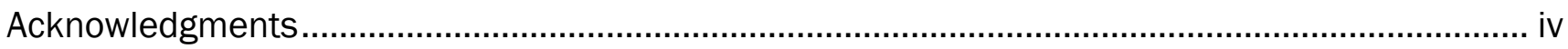

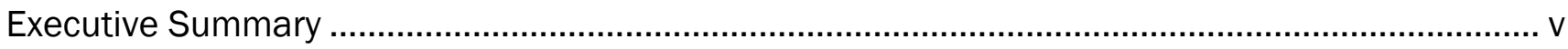

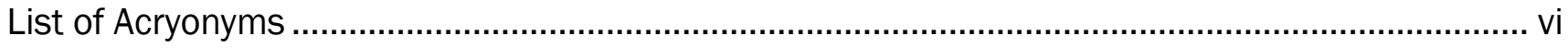

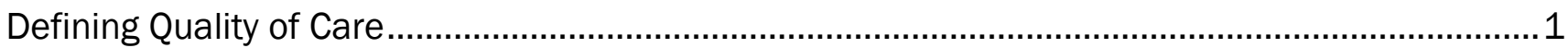

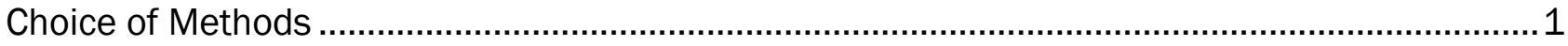

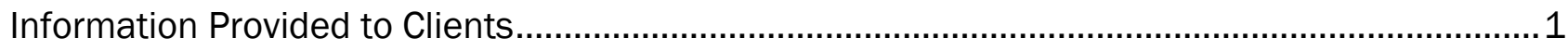

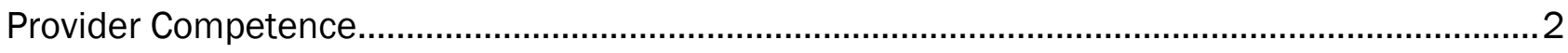

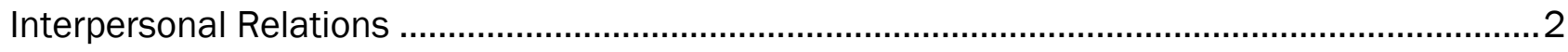

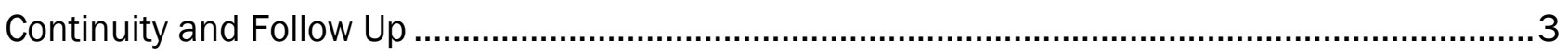

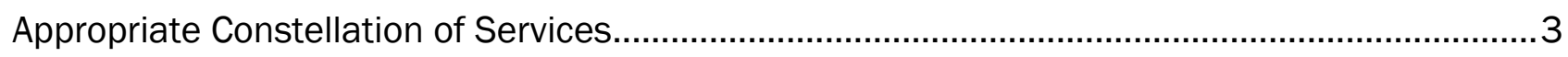

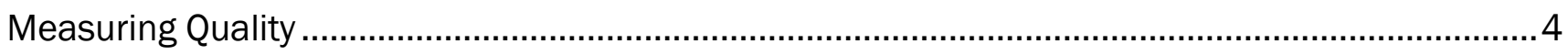

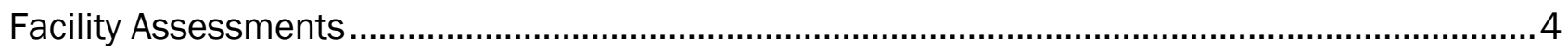

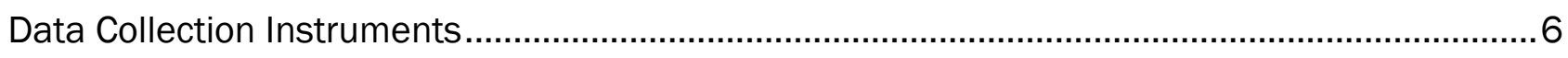

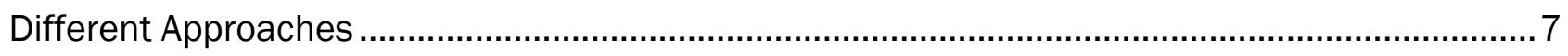

Methodological Concerns with Standard Data Collection Instruments.........................................

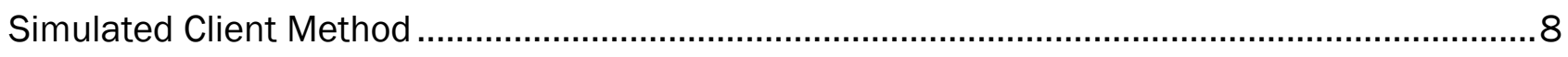

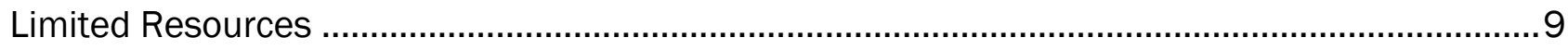

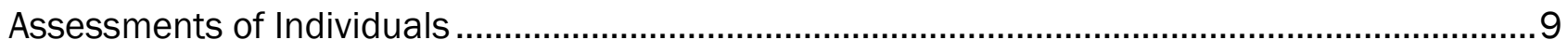

Items and Indicators Associated with Each Survey ……............................................................

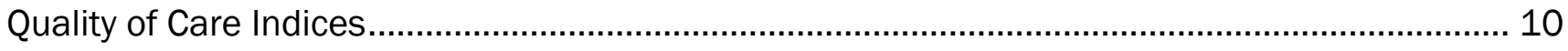

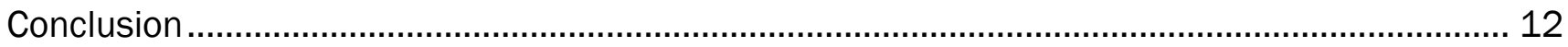

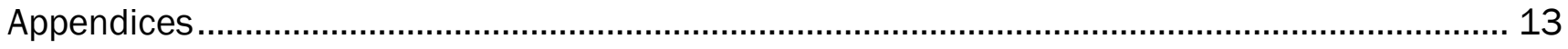

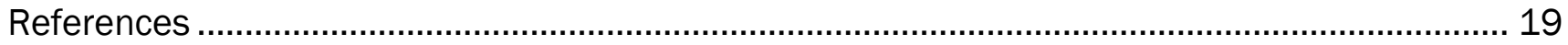




\section{Acknowledgments}

This review has been prepared by Katherine Tumlinson under the Measuring and Monitoring Quality of Services and Quality of Care project funded by a grant to the Population Council from the David and Lucile Packard Foundation. We gratefully acknowledge the Packard Foundation's support and encouragement for continuing research on the current state of quality of care.

The author also acknowledges financial support provided in part by the Eunice Kennedy Shriver National Institute of Child Health and Human Development of the National Institutes of Health, under Award T32HD007163. She also wishes to thank Anrudh K. Jain, Saumya RamaRao, and John W. Townsend of the Population Council for their guidance, expertise, insight, and helpful comments throughout the preparation of this working paper. 


\section{Executive Summary}

Despite successful efforts to increase financial and geographic access to family planning services in many parts of the developing world, large numbers of women with a desire to delay or limit future pregnancies are not using contraceptive methods. It has long been hypothesized that the poor quality of family planning service delivery in many resource constrained settings may act as a barrier to greater contraceptive use.

A framework first developed in the late 1980s defines the quality of family planning service delivery with six critical elements: choice of methods, information provided to clients, provider competence, interpersonal relations, follow up mechanisms, and appropriate constellation of services. This framework has guided the development of facility data collection instruments and indicators used in many large demographic surveys in countries around the world.

Currently several multi-country, large scale facility surveys incorporate indicators for measuring the quality of family planning service delivery, including the Demographic and Health Surveys' Service Provision Assessments (first implemented in 1985), the Measurement, Learning \& Evaluation Project's facility surveys, and service delivery facility questionnaires implemented by Performance Monitoring and Accountability 2020. These facility surveys use data collection tools such as facility audits, provider questionnaires, client questionnaires, and third party observation guides. A limited body of research indicates that the validity of these tools is low, however, while large variations in analytical approaches inhibit use of existing literature for summarizing progress or making comparisons over time or between countries.

Frequent use of quality indices may facilitate ease of analysis but creates challenges when translating research results into quality improvement policies and programs. Further discussion within the research community is warranted to ensure appropriate, feasible, and efficient strategies for measuring quality, and reducing quality-related barriers to optimal family planning use. 


\section{List of Acryonyms}

ClOMS Council for International Organizations of Medical Sciences

DHS Demographic and Health Survey

FP Family Planning

HIV/AIDS Human Immunodeficiency Virus/Acquired Immune Deficiency Syndrome

IIPS International Institute for Population Sciences

MLE Measurement, Learning \& Evaluation

QIQ Quick Investigation of Quality

$\mathrm{RH} \quad$ Reproductive Health

SARA Service Availability and Readiness Assessment

SPA Service Provision Assessment

UN United Nations

URHI Urban Reproductive Health Initiative

WHO World Health Organization 


\section{Defining Quality of Care}

Family planning (FP) programs were first implemented in developing countries in the 1950s and have successfully reduced fertility in many low income countries, most notably in Asia, Latin America, and North Africa ${ }^{1,2}$. Despite these successes, one out of every four married women in the world's 48 least developed countries still experience unmet FP need ${ }^{3}$. Many in the field of international FP have hypothesized, even after increased geographic and financial access to FP services, that their poor quality in low income settings may act as a barrier to greater contraceptive use ${ }^{4-8}$.

Broad support for promoting quality service delivery in FP programs is longstanding, rooted in the publication of a formal framework that outlined the essential elements of quality of care in FP service delivery 9,10 . This 1990 framework, developed by Judith Bruce, continues to be the foundation for defining the quality of FP services in the developing world. The Bruce framework includes aspects of both technical competency and interpersonal relations, reflecting and reinforcing a shift from demographic targets to a client-centered and reproductive rights approach ${ }^{10}$. The Bruce framework includes six elements that are essential for high quality FP services: choice of methods, information provided to clients, service provider competence, interpersonal relations, continuity and follow up mechanisms, and appropriate constellations of services.

\section{CHOICE OF METHODS}

Having a choice of methods means that a satisfactory selection, both of numbers and types of methods, is available on a reliable basis. Choice of methods is determined not only by physical availability of multiple methods but also by provder willingness to discuss multiple methods ${ }^{11}$. Choice is important for several reasons. Women and their partners have different reproductive needs at different stages of their lives, depending upon age, parity, type of relationship, and lactation status ${ }^{12}$. Couples who initially want to delay childbirth may later wish to space, and eventually limit, future pregnancies. A choice between short- and long-acting methods helps accommodate these life changes. Many women want to avoid undesirable side effects such as disruptions to menstrual patterns, headaches, weight gain, or nausea common with hormonal methods. Such side effects, which are impossible to predict, are consistently primary reasons reported by women for contraceptive discontinuation within the first year, particularly among women who were not told what to expect ${ }^{9,13-16}$. New contraceptive users may need to switch methods to find one with tolerable side effects. Additionally, the frequent occurrence of insufficient or inconsistent supplies in many international FP programs means that the provision of multiple methods increases the probability that an appropriate mix will be available at any one time ${ }^{9}$. In addition to these practical reasons, ensuring access to a variety of methods reaffirms the commitment to meeting individual women's needs rather than the blind promotion of a single method ${ }^{9 *}$. This is a mark of a client-oriented program.

\section{INFORMATION PROVIDED TO CLIENTS}

Providing information to clients means that they receive information from their service provider about a range of methods, including the advantages and disadvantages of each one, for a client's lifestyle and preferences, and instructions for use ${ }^{7}$. Provision of this information allows clients to understand they can choose from a variety of methods, each with different attributes. Clients can also be prepared to anticipate the possibility of side effects with certain hormonal methods, which may affect daily activities. As Bruce (1990) points out, a client is selecting a method that must fit into her daily life, including social activities and intimate sexual experiences. Unpredictable menstrual patterns, for example, may impact religious practices, work routines, and sexual experiences, and it is important for women to be prepared for that

\footnotetext{
* It should be noted that blind promotion of a single method is never good practice, even when additional methods are available.
} 
possibility ${ }^{9}$. By ensuring a client is informed and knowledgeable about potential side effects, a service provider is, in effect, helping the client manage the expectations of that contraceptive experience.

\section{PROVIDER`COMPETENCE}

Provider competence refers to the technical competence of a service provider and is separate from the the provider and client's interpersonal relationship. A competent provider demonstrates adequate technical competence and adherence to medical guidelines and protocols. Failure to observe safe clinical standards may not only result in harmful health outcomes but can generate negative rumors about FP programs or methods ${ }^{9}$. While other elements of quality may be measured through client interviews upon facility exit, measuring provider competence may prove more challenging, as clients are not sufficiently knowledgeable for judging a provider's technical competence. Training is often a proxy for competent clinical performance, although trained providers have been known to display incompetence ${ }^{17}$. Observations of client and provider interactions frequently are used for determining whether providers engage in such basic procedures as adequate record keeping and hand washing prior to physical exams.

In addition to inadvertent violations of medical guidelines, examples exist of providers imposing excessively restrictive medical criteria effectively blocking access to services for women who would like to avoid unintended pregnancy. Such behavior by service providers leads to what is commonly referred to as 'medical barriers' to contraceptive services ${ }^{5}$. Providers may restrict access for any number of reasons including client pregnancy, or misinformation such as outdated eligibility criteria, or personal bias ${ }^{5,18}$. Thanks in large part to improvements in provider training and more universal availability of FP guidelines and job aids ${ }^{19}$, medical barriers have greatly decreased in the past decade, but still exist ${ }^{18,19}$. Providers often deny contraception to non-menstruating women out of fear they may be pregnant, delaying method procurement for countless women, and this practice continues to be well-documented in many countries including Guatemala, Senegal, Jamaica, Kenya, and Ghana ${ }^{18}$. According to the World Health Organization (WHO), hormonal methods pose no medical danger to women or their pregnancy if accidentally used while pregnant (with the exception of the intrauterine device, which should not be inserted during pregnancy) ${ }^{20}$. Where inexpensive pregnancy tests are not available, providers wishing to be reasonably certain their clients are not pregnant can use a simple job aid developed by FHI360: the Pregnancy Checklist ${ }^{21}$. Quality assessment is necessary for determining extant disparities between standards of technical competence and actual practice in the field9.

\section{INTERPERSONAL RELATIONS}

Interpersonal relations are the personal or human aspects of service provision and are influenced by case loads, adequate supervision, and individual programs' priorities and goals ${ }^{12}$. A good interpersonal relationship involves a 'positive and productive' interaction between the client and provider-from the client's perspective 9 . Interpersonal relations between providers and clients may influence client confidence and satisfaction with a chosen method, as well as increasing the likelihood of a return visit ${ }^{9}$. Bruce suggests good interpersonal relations require understanding and respect from providers, including bi-directional communication and opportunities for clients to ask questions rather than receiving authoritative lectures 9 . This element may also include offering the client reassurance, caring, and sympathy when needed, and observance of a client's modesty wherever appropriate. A program focused primarily on achieving demographic targets can undermine providers' attempts to respond to the individual needs of their clients 9 . Interventions to improve client and provider interactions may include analysis of providers' case loads or increased managerial support for improved interpersonal performance ${ }^{7,9}$.

Although more commonly discussed in relation to maternal care and labor and delivery, interpersonal relations are also affected by corruption or disrespectful and abusive client treatment, which are not uncommon in developing countries but receive little attention, and yet have significant public health and human rights implications $22-26$. A 2011 report on health sector corruption commissioned by the United Nations (UN) Development Program identified papers from Asia, Africa, and Eastern Europe establishing a

† The term "provider" refers to any individual offering health care services, including counselors and auxiliary facility personnel. 
strong link between corrupt practices and negative health outcomes for poor women and children ${ }^{27}$. In Burkina Faso, for example, medical staff have reportedly demanded illegal payments for perinatal services already covered by government subsidies. These authors surmise such practices inhibit further reductions in maternal mortality 28 . A more recent study in Western Kenya found that providers frequently requested informal fees for contraceptive provision and engaged disrespectfully with their FP clients, potentially limiting access to contraceptive services ${ }^{29}$.

\section{CONTINUITY AND FOLLOW UP}

This element of quality ensures that follow up mechanisms are in place, such as scheduling future appointments or home visits, to encourage contraceptive continuity. Assisting clients with re-supply, or transition to a new method, may result in greater rates of contraceptive continuation, an important component of the overall prevalence rate ${ }^{9}$. Although many FP programs have traditionally focused on recruiting new clients, some research suggests that programs will be more successful both in achieving demographic targets and committing to individuals' welfare if they focus on good care to a small number of satisfied clients rather than recruiting large numbers of acceptors, many of whom will later discontinue their method due to dissatisfaction 7,30 .

\section{APPROPRIATE CONSTELLATION OF SERVICES}

Integrating FP into additional health services such as postpartum care, post-abortion care, HIV testing and counseling, child immunizations, and other services ensures their convenient access ${ }^{7}$. Integrated programs maintaining sufficient competence can result in increased points for client contact. In addition, integration recognizes the natural links between certain services such as FP and post-abortion care ${ }^{9}$. An analysis of post-abortion care in Lima, Peru in the late 1990s noted that failure to provide FP services to women after post-abortion care represents a double failure by the FP program: once when she experienced unintended pregnancy, resulting in an unsafe abortion, and a second time when she left treatment without a reliable FP method $^{31}$.

\section{Distinguishing Between Readiness and Service Quality}

In preparing to assess the relationship between quality and contraceptive use, some researchers have suggested that a high level of quality of care may not be realistic in the absence of adequate service infrastructure ${ }^{32}$, that those with direct client contact-service providers-need support through training, guidance, supplies, and educational materials to do their job welli3. RamaRao and Mohanam (2003) note that program managers have cited deficiencies in the service infrastructure as a key barrier to quality services. The term "quality" can be expanded to include not only the dynamics of interactions between clients and providers but also the degree to which facilities are prepared to offer services. The quality of service infrastructure is commonly referred to as a facility's "readiness," and this concept draws attention to factors that may impede provision of high quality services ${ }^{8}$. 


\section{Measuring Quality}

Since its introduction in 1990, the Bruce framework has become the recognized standard for defining quality in international FP4,10,12,34-37. Global adoption of the framework was only a first step: Figuring out how to implement and assess the quality of actual services posed a whole new set of challenges. By the mid-1990s contraceptive researchers were determined to identify specific areas for quality improvement within individual FP programs as well as understanding the true relationship between aspects of quality and contraceptive use and continuation ${ }^{35}$, but appropriate data collection instruments were in short supply. Researchers were beginning to understand the complexity of measuring quality within FP programs ${ }^{35}$, and were beginning to think about how to translate Bruce's framework into "programmatic reality 38 ." Avedis Donabedian, an early scholar in health care quality, pointed out that it can be a mistake to assume quality cannot be measured, yet an equal judgment error is to think such measurements are easy and precise, "as if a sack of potatoes was being weighed 39 ."

\section{FACILITY ASSESSMENTS}

\section{Situation Analysis}

The need for systematic, reliable, and relatively fast measures of quality led to the 1989 development of a set of instruments, the Situation Analysis ${ }^{40}$, by the Population Council's Africa Operations Research and Technical Assistance Project ${ }^{41}$, and later revised and adapted by other groups for regions outside subSaharan Africa. The first attempt to operationalize the concept of quality ${ }^{42}$, the first Situation Analysis aimed to describe both quality of care and the readiness of FP services, and to evaluate the impact of quality upon client satisfaction, the realization of reproductive goals, contraceptive prevalence, and fertility ${ }^{41}$.

Numerous situation analyses in developing countries over the past 20 years have resulted in refinements to the original instruments ${ }^{43}$. Situation Analysis originally included four basic data collection instruments for use at a service delivery point, although one or more could be ommitted by a research team, depending on available resources: a facility audit, observation guide for client and provider interactions, and questionnaires for interviewing both FP providers and exiting clients ${ }^{44,45}$. Implementation of large surveys like Situation Analysis is often costly and time consuming and can result in delayed and under-utilized data ${ }^{46}$. Increasing electronic data collection in developing countries may address some of these concerns in the future by reducing costs for data entry and study management, and by allowing for more rapid availability of raw data. These improvements may vastly improve research utilization by allowing for more timely policy and program recommendations.

\section{Quick Investigation of Quality}

An additional and similar set of tools useful in assessing quality, with relative speed, is the Quick Investigation of Quality: A User's Guide for Monitoring Quality of Care in Family Planning developed by MEASURE Evaluation in 200047. In the initial phase of development, MEASURE staff and collaborators identified more than 200 indicators of quality of care. In a series of 1998 and 1999 field tests designed to judge both feasibility of collecting these data and their corresponding reliability, the 200 indicators were narrowed to a list of 25 indicators for the final Quick Investigatrion of Quality (QIQ)8,48. Much like Situation Analysis, the QIQ includes several basic data collection instruments for assessing FP service quality but omits the service provider questionnaire; the three data collection methodologies included in the QIQ are the facility audit, observation guide for client and provider interactions, and questionnaire for interviews with exiting FP clients ${ }^{47}$. QIQ's instruments were field tested in Ecuador, Turkey, Uganda, and Zimbabwe. The authors of the QIQ note significant overlap between Situation Analysis indicators and instruments and those in the QIQ, but suggest QIQ's more concise nature is advantageous for programs wanting to monitor quality annually or biannually ${ }^{47}$. 


\section{Large Scale Facility Surveys}

Several large multi-country surveys collecting data on population and health indicators have incorporated some version of Situation Analysis or QIQ instruments to measure facility service quality. The Service Provision Assessment (SPA) is still in use, in select developing countries, by the Demographic and Health Survey (DHS), which is conducted in approximately 90 developing countries. DHS's SPA measures the quality of several types of services including child health, maternity and newborn care, sexually transmitted infections and other infectious diseases, and HIV/AIDS-in addition to FP services. Each SPA survey employs a representative sampling frame and includes a sample of over 400 facilities ranging from hospitals to health posts. A DHS SPA will typically have observations of about 4,000 client and provider interactions and will include interviews with a minimum of 1,000 health care providers ${ }^{45}$.

Although the development of Situation Analysis and corresponding SPA surveys enabled select countries to collect facility FP service delivery data, the DHS cannot link individual and facility data by individual woman, because women in the cross-sectional survey are not asked where they received services. The process of linking individual and facility DHS data by geographic location is still in the early stages of development ${ }^{49,50 \text {, }}$ and for this reason it is challenging to assess the relationship between quality and individual outcomes such as contraceptive use or continuation using DHS data. In addition, since 1997 only 14 countries-about 15 percent of all countries ever participating in a DHS survey-have conducted a SPA survey: Bangladesh in 2014 and 1999-2000, Egypt in 2004 and 2002, Ethiopia in 2014, Ghana in 2002, Guatemala in 1997 (but final report still pending), Haiti in 2013, Kenya in 2010, 2004 and 1999, Malawi in 2013-2014, Namibia in 2014 and 2009, Nepal in 2015, Rwanda in 2007 and 2001, Senegal in 2014 and 2012-2013, Tanzania in 2006 and 2014-2015, and Uganda in 2007. Three of these countries (Bangladesh, Egypt, Ghana) omitted at least one instrument, either the provider interview, exit interview, or observation protocol ${ }^{45}$.

Another large multi-country survey including facility quality assessments is the Measurement, Learning \& Evaluation (MLE) project implemented by the Carolina Population Center at the University of North Carolina. In 2009 the Bill and Melinda Gates Foundation funded the Urban Reproductive Health Initiative (URHI), a five year project for increasing the contraceptive prevalence rate in select urban areas of Kenya, Senegal, Nigeria, and Uttar Pradesh, India, and the MLE project is a six year project evaluating URHI collecting both individual and facility data. Facility data collection includes a facility audit as well as provider and exit interviews; no observations of the interactions between providers and clients were part of the baseline or endline facility data collection $\neq$. The MLE project contains sufficient information for linking individual and facility data, a significant advantage over previous facility data collection efforts.

A third large multi-country facility data collection effort, directed and supported by the Bill and Melinda Gates Institute for Population and Reproductive Health at the Johns Hopkins Bloomberg School of Public Health, is Performance Monitoring and Accountability 2020 (PMA2020), a five year project collecting data electronically for a focused number of indicators for more rapid FP program monitoring and evaluation. PMA2020 can engage in nationally representative data collection that is routine, low cost, and relatively rapid in its reporting. Ten countries in Africa and Asia have pledged resources for participation in PMA2020\$, and data have been collected in seven countries in sub-Saharan Africa: Burkina Faso, Democratic Republic of the Congo, Ethiopia, Ghana, Kenya, Nigeria, and Uganda. The use of emerging technology to collect these data electronically represents a large improvement in prior data collection efforts and greatly reduces many logistical challenges of collecting data with paper and pencil.

WHO recently began assessing developing country health facilities through its Service Availability and Readiness Assessment (SARA). SARA reports are available from 2010 from nine African countries. This data collection effort is unique because its data collection is limited to a facility audit, with priority on assessing key infrastructure resources and health facility readiness.

₹ In one of the five cities included in the Kenya midterm data collection (Kisumu), a facility study was conducted in 19 higher volume facilities. This small survey included an observation protocol.

$\S$ In total, 47 countries have made a commitment to expand access to voluntary, rights-based, high quality FP, including 36 of the 69 target countries. 
The Government of India, through the International Institute for Population Sciences (IIPS), collects district household and facility data in 611 districts. The facility data in these surveys are from facility audits only (much like SARA and PMA2020), and in the most recent round of data collection (2012 to 2013) IIPA conducted a "population-linked facility survey," allowing for assessments between quality of care and contraceptive use.

\section{DATA COLLECTION INSTRUMENTS}

Four basic data collection tools can be used at a facility to assess FP service quality: a facility audit, observation guide, and questionnaires for interviewing FP service providers and exiting clients. These tools can be used in any combination, and one or more can be omitted to reduce financial, logistical, or time burdens in facility data collection.

\section{Facility Audit}

A facility audit is conducted in collaboration with the facility's manager. This tool inventories supplies and equipment and collects information on infrastructure, record keeping, and management. The facility audit can identify method availability by noting current provision and availability of contraceptives and frequency of stock outs. It can also collect data on training and experience profiles of staff and integration of available services. The audit can also check for support of integrated services, adequacy of storage and standard operating procedures, consistent and sufficient stock of contraceptive commodities ${ }^{* *}$, and the presence of certain basic items such as sterile equipment, electricity, running water, and private examination rooms.

\section{Observation Guide}

An observation guide is a protocol for observing the client and provider interaction during the FP consultation and also allows assessment of the provider's adherence to national standards and guidelines. Observational data can be useful to examine elements of quality for which the client is not qualified to make an assessment, such as technical competence and implementation of good clinical practices. Observational data is also useful for measuring aspects of quality about which clients have limited recall. Additionally, a third party observer can assess provider performance through observation of actual service delivery, rather than relying on provider self-reports which may exaggerate the actual level of care provided.

\section{Exiting Client Questionnaire}

A questionnaire for interviewing FP clients as they exit the facility allows assessment of the client's perspective of the service delivery setting. Client exit interviews can collect data on the number of methods discussed by the provider, waiting times, client satisfaction, perceived treatment, and information given during the counseling session on topics including side effects, method use, and when to return to the facility. Client interview data can measure aspects of quality that are more subjective, such as respectful treatment, client satisfaction, and client perceptions.

\section{Service Provider Questionnaire}

A questionnaire for service provider interviews collects information from providers on training, supervision, and attitudes about their work environment. Providers can be asked about pre-service and in-service training, FP counseling procedures (including discussion of multiple methods, reproductive goals, and appropriate follow up, as well as various types of information on the client's chosen method), FP integration with other health care services, and quality assurance, among others. Provider interview data can be valuable in identifying limitations in provider knowledge of correct counseling procedures. For example, providers may be unaware of the necessity or value of discussing warning signs or asking about clients' reproductive goals.

\footnotetext{
** Harmonious suite of indicators to measure contraceptive stock outs draws from four categories (products or methods offered, pointin-time stock outs, range of methods available, and frequency and duration of stock outs over time) and specific indicators for each category can be found on the Reproductive Health Supplies web site: 


\section{DIFFERENT APPROACHES}

These different tools allow for different approaches to collecting quality data, and each have distinct advantages. The facility audit can capture method availability by noting current supply and frequency of stock outs. The facility audit is also uniquely designed for objectively assessing the adequacy of a large number of components of facility infrastructure and is, therefore, the best tool for measuring readiness. Provider interview data, on the other hand, can be valuable for identifying low provider knowledge of correct counseling procedures. Low prevalence of an indicator from this self-reported data can highlight deficiencies in provider knowledge. Client interview data is uniquely able to measure more subjective constructs like respectful treatment, client satisfaction, and perceptions of quality. Lastly, observational data can be useful for elements of quality where the client is not qualified to make an assessment-such as technical competence-or has limited recall. Table 1 illustrates the specific indicators within each tool that can be used to measure each element of quality of care and readiness.

Table 2 demonstrates several large scale demographic surveys and the specific instruments they include in their process of assessing quality of care or facility readiness. Table 2 also includes an indication of whether or not each of these surveys is able to link individual and facility data by individual woman.

\section{METHODOLOGICAL CONCERNS WITH STANDARD DATA COLLECTION INSTRUMENTS}

\section{Courtesy Bias}

It should be noted that the structured format of questions used in the exit interview combined with the close proximity to facility personnel often results in courtesy bias, whereby clients feel uncomfortable reporting negative aspects of care. Courtesy bias tends to skew results related to client satisfaction in a positive direction of higher perceived quality $40,47,48,51$. At a minimum-i.e. assuming the errors in measurement resulting from courtesy bias occur completely at random-such bias may result in inflated standard errors and results that incorrectly appear insignificant ${ }^{52}$.

\section{Recall Bias}

When interviewing FP clients just before they exit the health facility, it is important to remember that these clients may have difficulty recalling the information that they received during their FP counseling session. Even when providers discuss possible side effects of the client's chosen method, the client may not be able to remember if the information was given to them. They may also feel that some of the information they discussed with their provider is private and may therefore deliberately omit some information during the interview to shield their privacy. Authors of the QIQ suggest using a client interview instrument containing only a limited number of questions to reduce interviewee fatigue and subsequent lack of recall 47 . It may, however, be the case that a client's lack of recall of the information provided is a relevant measure of quality. Whether or not poor recall introduces bias into a study depends on the research question.

\section{Validity of Provider Interviews and Social Desirability Bias}

Providers may report their intentions or an "ideal" of service delivery rather than what they do in practice ${ }^{40}$. The desire to report what they believe they should be doing, rather than providing an accurate description of existing services, could result from social desirability bias, whereby a respondent wants to please the data collector, or may result from fear of job loss if their actual practices are revealed. As with courtesy bias, the inflation of provider competence and service delivery practices likely skews quality in a positive direction.

\section{Hawthorne Effect}

Direct observation of client and provider interactions is a means of avoiding exit interview courtesy bias or provider interview misinformation, whereby a third party objectively and systematically observes and records the interactions between clients and providers. Direct observation is not without problems ${ }^{40,47}$, however, 
with providers' awareness of their observation a primary concern, making it more likely that they change their behaviors and act differently than when alone with a client. Providers are on their "best behavior" during direct observations ${ }^{47,48}$. During a 1991 situation analysis in Kenya, one provider reported, "I usually do not have this much time for clients, but in view of your presence, I had better try to do an especially good job ${ }^{42}$."

These biases and methodological concerns may not, in some instances, interfere with study objectives. Some prior studies' objectives were best achieved by investigating client or provider "perceptions" of quality without focusing on whether perceived quality differs from actual provider behavior ${ }^{51,53-61}$. The objectives of many quality of care studies in international FP require measures of actual provider behavior, however, and in these studies, biased information may result in false implications and conclusions.

\section{SIMULATED CLIENT METHOD}

To avoid Hawthorne bias while still observing client and provider interactions, one possible solution is audioor video recording those interactions, for later review ${ }^{40}$. This method, however, is not widely used in developing countries. A more commonly employed approach is the mystery or "simulated" client method62${ }^{69}$, when a woman pretending to be an actual new FP client presents at a health facility for a FP counseling session, whereby the provider is unaware that the "client" has a research agenda65. After the FP counseling session, the "undercover" data collector then records or reports her observations. The primary benefit of this method is its unobtrusiveness and likelihood of greater accuracy than a third party observation, since it collects data on actual practice that would be difficult to obtain through other means ${ }^{65}$. Simulated clients can be useful when new client attendance is low or when clients decline to be interviewed 40,70 . In a 1990 situation analysis in Kenya, only 48 of the 99 selected clinics had new clients on the day they were visited, and as a result, the analysis was considerably restricted ${ }^{42}$.

The key to accuracy in the simulated client method is the employment of simulated clients who present realistically to the provider they will both patronize and observe, and who are representative in their presentation of the typical client population for the clinic. Simulated clients must have a strong recall of events during their counseling session ${ }^{65}$. It can be difficult to recruit such clients, especially in small communities where the simulated clients are more likely to be recognized ${ }^{71}$. A study of the reliability of data obtained from simulated clients in a 1991 study in Peru used pairs of concealed observers and found low levels of agreement (interclass correlation $=.5$ ) within pairs, indicating the likelihood of rating errors ${ }^{72}$. In studies in which a single provider is evaluated by a single observer, doubt must be expressed about the reliability of the evaluation. One solution is the use of checklists to help the simulated client recall and objectively evaluate providers.

In addition to the many methodological benefits of using simulated clients to collect data on provider-client interactions, there are ethical concerns with this type of data collection ${ }^{65}$. Because it is inherently necessary for simulated clients to engage in subterfuge by masking their true purpose and intent, obtaining informed consent from providers is not possible 63 . One possible negative consequence of this approach is that once providers become aware that they have been observed without their consent, it is likely to undermine the relationship and rapport between providers and their supervisors who have approved such methods. In addition, it's possible that clients may have to undergo an unwanted physical exam to maintain the ruse of their visit8,65. Guidelines for addressing ethical concerns in epidemiologic research published by the Council for International Organizations of Medical Sciences (CIOMS) suggest absence of informed consent may be acceptable in scenarios where full disclosure would interfere with the study purpose ${ }^{65}$. Huntington and Schuler (1993) also suggest ways to uphold ethical integrity while still gaining the benefits of this approach. One solution is to disclose to the provider the possibility of simulated client visits at a future date so they are aware that they will be observed at some point but will not know when such observations will occur, inhibiting their motivation to change their behavior. It may also be possible to train simulated clients on ways to avoid unwanted exams ${ }^{8}$. It is also a good idea to discuss all ethical concerns with clinic managers to find ways to implement client simulations with integrity ${ }^{63}$. Many feel the validity benefits of employing simulated clients outweigh these concerns ${ }^{71}$. 


\section{LIMITED RESOURCES}

Some researchers suggest choosing between exit interviews and direct observations in settings where research resources are scarce, given that some studies find a high degree of agreement between the two instruments, particularly for indicators measuring interpersonal relations ${ }^{48}$. Others suggest both exit interviews and direct observations rather than substituting one for the other, given the unique perspectives provided by each ${ }^{47}$. Only client exit interviews can provide clients' perspectives, yet clients often have difficulty expressing dissatisfaction with provider performance during exit interviews, either due to cultural norms discouraging negative criticism or fear their providers may learn of their comments ${ }^{8}$. Poor performance by a provider will be evident to an observer even when a client is reluctant to indicate it. Clients cannot provide information on specific clinical practices related to technical competence, because they usually do not possess the necessary clinical backgrounds to assess this aspect of care. Selecting only one of the two instruments, therefore, limits the number and types of indicators that can measure quality 48 . Collecting the same information with more than one instrument also allows researchers to conduct "internal validity checks" 11 . A limited number of studies investigate the reliability (found reasonable ${ }^{48,73}$ ) and validity (found to be consistently low ${ }^{74}$ ) of these tools for measuring quality. Additional studies may be needed as well as strategies for helping policy makers understand the limitations of specific data collection instruments.

\section{ASSESSMENTS OF INDIVIDUALS}

Many large demographic surveys collecting facility data also collect individual data within a representative sample of women of reproductive age, and these data can also be used to assess the quality of FP service delivery. All three of the large surveys discussed (DHS, MLE, PMA2020) collect this type of individual data. Indicators commonly included within these surveys to measure service quality are:

- Were you told about other methods?

- Were you told about side effects?

- Were you told what to do if you experience side effects?

\section{ITEMS AND INDICATORS ASSOCIATED WITH EACH SURVEY}

It is useful to understand which surveys include items for addressing each of the six elements of quality included in the Bruce framework. Table 3 (Appendix 3) displays the questions or items included in facility audits conducted by seven different survey mechanisms. Additionally, a list of the facility and aggregate indicators that can be calculated from these items is also included. Not all elements of quality can be measured by a facility audit; the elements included in Table 3 therefore include: choice and constellation of services as well as infrastructure or readiness.

Table 4 (Appendix 4) displays the questions used in facility based client exit interviews and cross-sectional surveys and the corresponding facility and aggregate indicators. Like Table 3 , this table is organized by the element of quality of care and includes the following elements: choice, information, client and provider relations, and follow up mechanisms. 


\section{Quality of Care Indices}

Many small studies pick and choose elements of quality based on available secondary data or the feasibility of primary data. As a result of inconsistently applied measures of quality, it is difficult to make comparisons across geographic regions or time periods among these smaller studies. A handful of larger and more comprehensive studies of quality have combined specific indicators or aspects of quality into an overall index of quality of care ${ }^{70,75-78}$, and a review of these studies is included in this paper, with details of how those quality of care indices were calculated.

A 1992 study in Peru used eight different data collection instruments, and created two summary indexes:

"For this particular analysis, two summary indexes of quality were constructed: one based on eight dimensions and one based on three dimensions...For the eight-dimension index, nearly 150 variables were selected for the analysis from the eight instruments. The major criterion for inclusion was that the variable assessed, preferably directly but in some cases indirectly, some aspect of quality of care."

An appendix of the study report provides additional details ${ }^{70}$.

In a 1997-1998 Philippines study, quality of care is presented as an index variable with 24 items:

"Reflecting five different aspects of the care-giving process: the assessment of client needs, the information conveyed, the choices offered, whether the client was treated well by the provider and whether she was linked to follow-up services. These aspects of quality were selected because they represent different dimensions of the process. They are based on theoretic and programmatic insights on what the care-giving process should entail. We weighted these 24 items equally, because we deemed them all to be of equal importance. The variable combining the five aspects of care attempts to characterize total quality and is scored as low, medium and high to differentiate among levels of overall care. The medium level is defined as quality within one-half of a standard deviation of the mean; values falling outside the range of medium quality were considered the low and high levels of total quality 79 ."

A contemporaneous study in Senegal measured multiple indicators of quality of four aspects from the Bruce framework (choice, information, interpersonal relations, continuity) and combined all indicators into a single index ranging on a scale from one to five ${ }^{78}$.

A study of the relationship between quality and continuation in Vietnam from the same period measured health center quality as "an index score of service delivery infrastructure (e.g. electricity, running water), medical equipment (e.g. delivery kit, linens), essential medicines (e.g. penicillin, folic acid, iron tablets), number of contraceptive methods available on the day of visit, and number of staff trained in family planning75." Details of how to interpret the quality of care index are not immediately clear from the manuscript, a common problem with indices, and creates a challenge when attempting to translate research findings into quality improvement policies and practices.

A more recent study in Egypt used individual facility data from the 2003 DHS. Twenty-two different indicators measured four elements of quality: counseling, examination room, method choice, and training and supervision; and an index was created combining these four elements ${ }^{77}$.

"The quality indices for each quality dimension of family planning services are the total availability of items in each dimension standardized to add to 25 . The total family planning quality index is the sum of all 4 component scores and has the maximum value of 100 [Table 1]. The differences in quality of family planning services are measured by dividing the total scores into three quintiles representing the low, medium, and high quality of family planning services."

Another recent study in Nepal created an index for just one component of quality (indicators from other aspects of quality were not combined): information provided to clients ${ }^{76}$. The manuscript describes how the index was constructed and analyzed: Women were also asked detailed questions of whether they were given information on possible side effects, disadvantages, advantages, warning signs, recognizing complications, and what to do if they occur. Responses to each aspect were dichotomized: whether women were given information on the specific aspect or otherwise-no information or did not recall. The six items were totaled, 10 
for an index ranging from zero to six, which was trichotomized in the analysis for low level of information [01], moderate level of information [2-4], or high level of information [5-6].

Tumlinson et al. assessed care quality in urban Kenya, using facility data (provider and client interviews and facility audit data) collected in 2011 , and created 48 quality variables corresponding to the six Bruce elements. Factor analysis grouped similar variables, which reduced the quality exposure variables from 48 to 35. The remaining 35 variables did not demonstrate sufficient correlation to justify further data reduction, which precluded preparation of an overall quality of care index and demonstrates a potential problem with creating an index score for assessing quality of care and its relationship to contraceptive use: Not all indicators of quality are sufficiently correlated to group into a single variable.

The benefits and limitations of creating index or composite variables from numerous quality of care variables should be discussed within the community of FP researchers, considering strategies such as the principle component analysis in the recent DHS Analytical Studies 44: Assessing the Quality of Care in Family Planning, Antenatal, and Sick Child Services in Health Facilities in Kenya, Senegal, and Namibia. 


\section{Conclusion}

Over the past two decades quality of care has become the issue for championing within the field of international family planning. In response to the development of the Bruce framework, over the last 25 years many facility surveys have been developed including Population Council's Situation Analysis, MEASURE Evaluation's Quick Investigation of Quality, DHS's Service Provision Assessment, WHO's Service Availability and Readiness Assessment, along with the facility tools in UNC's Measurement, Learning \& Evaluation Project and Performance, Monitoring and Accountability 2020's facility tools. Several of these surveys also include cross-sectional individual questionnaires within randomly selected households. Within each facility survey, a combination of tools can include a facility audit, observation protocol, or questionnaires for interviewing providers or clients, each with unique attributes, and their uses, or not, depend upon a study's purpose.

Despite widespread endorsement of the Bruce framework and development of standardized data collection instruments, obstacles to accurate measures of quality remain. Few countries collect facility data, and even fewer use observations of client and provider interactions for verifying the data from exit and provider interviews. Incorporation of the simulated client method could provide additional helpful information but is infrequently used, nor has a standardized tool been developed. In addition, within studies investigating the quality of FP services there is great diversity in how quality is defined and which elements of quality of care are considered most important, with no agreed set of indicators. Inconsistent definitions of quality pose a challenge to summarizing results of studies investigating quality of care in FP programs ${ }^{80}$. 


\section{Appendices}

\begin{tabular}{|c|c|c|c|c|}
\hline $\begin{array}{l}\text { Element } \\
\text { of quality }\end{array}$ & $\begin{array}{l}\text { Items included } \\
\text { in a facility audit }\end{array}$ & $\begin{array}{l}\text { Items included } \\
\text { in provider } \\
\text { questionnaire }\end{array}$ & $\begin{array}{l}\text { Items included } \\
\text { in existing client } \\
\text { questionnaire }\end{array}$ & $\begin{array}{l}\text { Items included } \\
\text { in observation (third party } \\
\text { of simulated client) guide }\end{array}$ \\
\hline \multirow{2}{*}{$\begin{array}{l}\text { Choice } \\
\text { of Methods }\end{array}$} & \multirow{2}{*}{$\begin{array}{l}\text { * Does this facility } \\
\text { provide the following FP } \\
\text { methods/services? } \\
\text { (list all) } \\
\text { * Is the method currently } \\
\text { available? } \\
\text { * Has it been out of stock } \\
\text { in the past month } \\
\text { or year? }\end{array}$} & $\begin{array}{l}\text { * Do you provide } \\
\text { information about } \\
\text { different methods? }\end{array}$ & $\begin{array}{l}\text { * Did your provider } \\
\text { provide information } \\
\text { about different FP } \\
\text { methods? }\end{array}$ & $\begin{array}{l}\text { * Which methods did } \\
\text { the provider mention } \\
\text { to the client? }\end{array}$ \\
\hline & & $\begin{array}{l}\text { * Do you discuss } \\
\text { the client's FP } \\
\text { preferences? }\end{array}$ & $\begin{array}{l}\text { * Did your provider ask } \\
\text { about your method } \\
\text { of choice? }\end{array}$ & $\begin{array}{l}\text { * Did the provider ask } \\
\text { about/discuss the client's } \\
\text { preferred method or method } \\
\text { of choice? }\end{array}$ \\
\hline \multirow{5}{*}{$\begin{array}{l}\text { Information } \\
\text { Given to User }\end{array}$} & \multirow{5}{*}{ NA } & $\begin{array}{l}\text { * Do you help a client } \\
\text { select a suitable } \\
\text { method? }\end{array}$ & $\begin{array}{l}\text { * Did your provider help } \\
\text { you select a method? }\end{array}$ & $\begin{array}{l}\text { * Did the provider help the client } \\
\text { select an appropriate } \\
\text { method? }\end{array}$ \\
\hline & & $\begin{array}{l}\text { * Do you explain } \\
\text { the side effects? }\end{array}$ & $\begin{array}{l}\text { * Did your provider talk } \\
\text { about possible side } \\
\text { effects? }\end{array}$ & $\begin{array}{l}\text { * Did the provider tell the client } \\
\text { what side effects to expect } \\
\text { with her chosen method? }\end{array}$ \\
\hline & & $\begin{array}{l}\text { * Do you tell clients } \\
\text { how to manage } \\
\text { side effects? }\end{array}$ & $\begin{array}{l}\text { * Did the provider tell you } \\
\text { what to do if you } \\
\text { experience side } \\
\text { effects? }\end{array}$ & $\begin{array}{l}\text { * Did the provider tell the client } \\
\text { how to manage the side } \\
\text { effects? }\end{array}$ \\
\hline & & $\begin{array}{l}\text { * Do you explain } \\
\text { specific medical } \\
\text { reasons to return? }\end{array}$ & $\begin{array}{l}\text { * Did the provider tell you } \\
\text { what to do if you have } \\
\text { any problems? }\end{array}$ & $\begin{array}{l}\text { * Did the provider discuss } \\
\text { warning signs/management } \\
\text { of warning signs? }\end{array}$ \\
\hline & & $\begin{array}{l}\text { * Do you explain } \\
\text { hor to use } \\
\text { the selected } \\
\text { method? }\end{array}$ & $\begin{array}{l}\text { * Did your provider } \\
\text { explain how to use } \\
\text { the method? }\end{array}$ & $\begin{array}{l}\text { * Did the provider tell the client } \\
\text { how to use her selected } \\
\text { method? }\end{array}$ \\
\hline $\begin{array}{l}\text { Provider } \\
\text { Competence }\end{array}$ & NA & $\begin{array}{l}\text { * Have you received } \\
\text { any pre- or in- } \\
\text { service training } \\
\text { on FP provision, } \\
\text { and how long ago? }\end{array}$ & NA & $\begin{array}{l}\text { * Was the client's medical } \\
\text { history taken? }\end{array}$ \\
\hline \multirow{3}{*}{$\begin{array}{l}\text { Client } \\
\text { and Provider } \\
\text { Relations }\end{array}$} & \multirow{3}{*}{ NA } & & $\begin{array}{l}\text { * During your visit, } \\
\text { how were you treated } \\
\text { by the provider? }\end{array}$ & $\begin{array}{l}\text { * Did the provider give the client } \\
\text { a respectful and/or friendly } \\
\text { greeting? }\end{array}$ \\
\hline & & $\begin{array}{l}\text { * Do you identify } \\
\text { reproductive goals } \\
\text { of the client? }\end{array}$ & $\begin{array}{l}\text { * Did your provider ask } \\
\text { your reproductive goal? }\end{array}$ & $\begin{array}{l}\text { * Did the provider enquire } \\
\text { about the client's RH goals } \\
\text { and plans? }\end{array}$ \\
\hline & & & $\begin{array}{l}\text { * Did the provider ask } \\
\text { you if you had any } \\
\text { questions? }\end{array}$ & $\begin{array}{l}\text { * Did the provider ask the client } \\
\text { if she had any questions? }\end{array}$ \\
\hline $\begin{array}{l}\text { Continuity } \\
\text { Mechanism }\end{array}$ & NA & $\begin{array}{l}\text { * Do you explain } \\
\text { when to return } \\
\text { for follow up? }\end{array}$ & $\begin{array}{l}\text { * Did your provider tell } \\
\text { you when to return } \\
\text { for follow up? }\end{array}$ & $\begin{array}{l}\text { * Did the provider inform } \\
\text { the client when to return } \\
\text { for a follow up visit? }\end{array}$ \\
\hline $\begin{array}{l}\text { Appropriate } \\
\text { Constellation } \\
\text { of Services }\end{array}$ & $\begin{array}{l}\text { * Is FP provided } \\
\text { during postpartum } \\
\text { health care visits? } \\
\text { * Is FP provided } \\
\text { during post-abortion } \\
\text { health care visits? } \\
\text { * Is FP provided } \\
\text { during maternal and } \\
\text { child health visits? } \\
\text { * Is FP provided } \\
\text { during vaccination } \\
\text { visits? } \\
\text { * Is FP provided } \\
\text { during HIV services? }\end{array}$ & $\begin{array}{l}\text { * Do you offer FP } \\
\text { to clients who come } \\
\text { in for other types } \\
\text { of services? }\end{array}$ & $\begin{array}{l}\text { * In addition to the FP } \\
\text { services you received, } \\
\text { did you receive any } \\
\text { other health services } \\
\text { from the service } \\
\text { provider today? }\end{array}$ & $\begin{array}{l}\text { * In addition to the FP services } \\
\text { you received, did the client } \\
\text { receive any other health } \\
\text { services from the service } \\
\text { provider today? }\end{array}$ \\
\hline
\end{tabular}


Table 1, Continued

\begin{tabular}{|c|c|c|c|c|}
\hline $\begin{array}{l}\text { Element } \\
\text { of quality }\end{array}$ & $\begin{array}{l}\text { Items included } \\
\text { in a facility audit }\end{array}$ & $\begin{array}{l}\text { Items included } \\
\text { in provider } \\
\text { questionnaire }\end{array}$ & $\begin{array}{l}\text { Items included } \\
\text { in existing client } \\
\text { questionnaire }\end{array}$ & $\begin{array}{l}\text { Items included } \\
\text { in observation (third party } \\
\text { of simulated client) guide }\end{array}$ \\
\hline $\begin{array}{l}\text { Readiness } \\
\text { or } \\
\text { Infrastructure }\end{array}$ & $\begin{array}{l}\text { Does the facility have: } \\
\text { private exam room, } \\
\text { running water, } \\
\text { electricity, basic } \\
\text { supplies, FP guidelines, } \\
\text { quality assurance } \\
\text { measures, etc.? }\end{array}$ & NA & NA & NA \\
\hline $\begin{array}{l}\text { Client } \\
\text { Satisfaction }\end{array}$ & NA & NA & $\begin{array}{l}\text { * How satisfied were you } \\
\text { with the services you } \\
\text { received today? }\end{array}$ & NA \\
\hline
\end{tabular}




\section{APPENDIX 2: TABLE 2 Surveys collecting data related to family planning quality of care}

and instruments included

\begin{tabular}{|c|c|c|c|c|c|c|}
\hline \multirow[b]{2}{*}{ Survey } & \multicolumn{4}{|c|}{ Facility Data } & \multirow{2}{*}{$\begin{array}{c}\text { Individual Data } \\
\text { Women's } \\
\text { questionnaire? }\end{array}$} & \multirow{2}{*}{$\begin{array}{l}\text { Able to link } \\
\text { facility and } \\
\text { individual } \\
\text { data? }\end{array}$} \\
\hline & $\begin{array}{l}\text { Facility } \\
\text { Audit? }\end{array}$ & $\begin{array}{l}\text { Provider } \\
\text { Interview? }\end{array}$ & $\begin{array}{c}\text { Client } \\
\text { Interview? }\end{array}$ & $\begin{array}{c}\text { Third Party } \\
\text { Observation? }\end{array}$ & & \\
\hline $\begin{array}{l}\text { Demographic } \\
\text { and Health } \\
\text { Survey }\end{array}$ & Yes & Yes & Yes & Yes & Yes & No \\
\hline $\begin{array}{l}\text { Measurement, } \\
\text { Learning \& } \\
\text { Evaluation } \\
\text { Project }\end{array}$ & Yes & Yes & Yes & No & Yes & Yes \\
\hline $\begin{array}{l}\text { International } \\
\text { Institute for } \\
\text { Population } \\
\text { Sciences* }\end{array}$ & Yes & No & No & No & Yes & Yes \\
\hline $\begin{array}{l}\text { Performance, } \\
\text { Monitoring, } \\
\text { and } \\
\text { Accountability }\end{array}$ & Yes & No & No & No & Yes & No \\
\hline $\begin{array}{l}\text { WHO Service } \\
\text { Availability and } \\
\text { Readiness } \\
\text { Assessment } \\
\text { (SARA) }\end{array}$ & Yes & No & No & No & No & No \\
\hline
\end{tabular}

*This survey is conducted at the district level in India 
APPENDIX 3: TABLE 3 Questions and computable indicators of quality from facility audits

\begin{tabular}{|c|c|c|c|c|c|c|c|}
\hline \multirow{3}{*}{ Questions and computable indicators } & \multicolumn{7}{|c|}{ Facility audits } \\
\hline & \multirow{3}{*}{ SA } & \multirow{3}{*}{ QIQ } & \multirow[b]{2}{*}{ SARA } & \multirow{2}{*}{$\begin{array}{l}\text { DHS- } \\
\text { SPA }\end{array}$} & \multirow{3}{*}{ MLE } & \multirow{2}{*}{$\begin{array}{l}\text { PMA } \\
2020\end{array}$} & \multirow[b]{2}{*}{ IIPS } \\
\hline & & & & & & & \\
\hline \multicolumn{5}{|l|}{ Choice: } & & & \\
\hline \multicolumn{8}{|l|}{ Questions/Items } \\
\hline Does this facility provide the following methods? & $\checkmark$ & $\checkmark$ & $\checkmark$ & $\checkmark$ & $\checkmark$ & $\checkmark$ & --- \\
\hline Are they currently available/observed? & $\checkmark$ & $\checkmark$ & $\checkmark$ & $\checkmark$ & $\checkmark$ & $\checkmark$ & --- \\
\hline Have there been any stock outs in last three, six or 12 months? & $\checkmark$ & $\checkmark$ & $\checkmark$ & -- & $\checkmark$ & $\checkmark$ & -- \\
\hline \multicolumn{8}{|l|}{ Facility Indicators, Computable } \\
\hline Number of methods provided & $\checkmark$ & $\checkmark$ & $\checkmark$ & $\checkmark$ & $\checkmark$ & $\checkmark$ & --- \\
\hline Number of methods provided and currently available & $\checkmark$ & $\checkmark$ & $\checkmark$ & $\checkmark$ & $\checkmark$ & $\checkmark$ & -- \\
\hline $\begin{array}{l}\text { Number of methods provided and not stocked out in previous six months or } \\
\text { one year }\end{array}$ & $\checkmark$ & $\checkmark$ & $\checkmark$ & -- & $\checkmark$ & $\checkmark$ & -- \\
\hline \multicolumn{8}{|l|}{ Aggregate Indicators, Computable } \\
\hline Mean number of methods provided & $\checkmark$ & $\checkmark$ & $\checkmark$ & $\checkmark$ & $\checkmark$ & $\checkmark$ & --- \\
\hline Mean number of methods provided and currently available & $\checkmark$ & $\checkmark$ & $\checkmark$ & $\checkmark$ & $\checkmark$ & $\checkmark$ & -- \\
\hline $\begin{array}{l}\text { Mean number of methods provided and not stocked out in previous six } \\
\text { months or one year }\end{array}$ & $\checkmark$ & $\checkmark$ & $\checkmark$ & -- & $\checkmark$ & $\checkmark$ & -- \\
\hline$\%$ of facilities providing at least one longer acting reversible method & $\checkmark$ & $\checkmark$ & $\checkmark$ & -- & $\checkmark$ & $\checkmark$ & -- \\
\hline$\%$ of facilities providing three or more methods & $\checkmark$ & $\checkmark$ & $\checkmark$ & -- & $\checkmark$ & $\checkmark$ & -- \\
\hline \multicolumn{8}{|l|}{ Constellation of services: } \\
\hline \multicolumn{8}{|l|}{ Questions/Items } \\
\hline $\begin{array}{l}\text { Is family planning offered during other types of visits such postpartum, post- } \\
\text { abortion, maternal and child health, vaccination, or HIV service visits? }\end{array}$ & -- & -- & --- & $\checkmark$ & $\checkmark$ & $\checkmark$ & -- \\
\hline \multicolumn{8}{|l|}{ Facility Indicators, Computable } \\
\hline Number and type of different services with which family planning is integrated & -- & -- & --- & $\checkmark$ & $\checkmark$ & $\checkmark$ & -- \\
\hline \multicolumn{8}{|l|}{ Aggregate Indicators, Computable } \\
\hline$\%$ of facilities that integrate family planning into other health care services & -- & -- & --- & $\checkmark$ & $\checkmark$ & $\checkmark$ & --- \\
\hline \multicolumn{8}{|l|}{ Infrastructure: } \\
\hline \multicolumn{8}{|l|}{ Questions/Items } \\
\hline $\begin{array}{l}\text { Which of the following are available and in working order: sterilizing } \\
\text { equipment, gloves, blood pressure cuff, specula, electricity, running water, etc. }\end{array}$ & $\checkmark$ & $\checkmark$ & $\checkmark$ & $\checkmark$ & $\checkmark$ & $\checkmark$ & -- \\
\hline Does the facility have private exam rooms (visual and audial privacy)? & $\checkmark$ & -- & $\checkmark$ & $\checkmark$ & $\checkmark$ & $\checkmark$ & -- \\
\hline Does the facility have family planning guidelines? & --- & $\checkmark$ & $\checkmark$ & $\checkmark$ & $\checkmark$ & -- & --- \\
\hline $\begin{array}{l}\text { Does the facility have any type of quality assurance committee or staff } \\
\text { meetings that assure quality control for family planning service delivery? }\end{array}$ & -- & $\checkmark$ & --- & $\checkmark$ & $\checkmark$ & -- & -- \\
\hline \multicolumn{8}{|l|}{ Facility Indicators, Computable } \\
\hline Number of basic items that are available and functioning & $\checkmark$ & $\checkmark$ & $\checkmark$ & $\checkmark$ & $\checkmark$ & $\checkmark$ & --- \\
\hline There is visual and audial privacy & $\checkmark$ & -- & $\checkmark$ & $\checkmark$ & $\checkmark$ & $\checkmark$ & -- \\
\hline Family planning guidelines are present & -- & $\checkmark$ & $\checkmark$ & $\checkmark$ & $\checkmark$ & -- & -- \\
\hline Quality assurance measures are in place & -- & -- & --- & $\checkmark$ & $\checkmark$ & -- & -- \\
\hline \multicolumn{8}{|l|}{ Aggregate Indicators, Computable } \\
\hline $\begin{array}{l}\text { Percent of facilities with most or all of the basic items available and } \\
\text { functioning }\end{array}$ & $\checkmark$ & $\checkmark$ & $\checkmark$ & $\checkmark$ & $\checkmark$ & $\checkmark$ & -- \\
\hline$\%$ of facilities with visual and audial privacy & $\checkmark$ & -- & $\checkmark$ & $\checkmark$ & $\checkmark$ & $\checkmark$ & -- \\
\hline$\%$ of facilities with family planning guidelines present & -- & $\checkmark$ & $\checkmark$ & $\checkmark$ & $\checkmark$ & -- & -- \\
\hline$\%$ of facilities with quality assurance measures in place & -- & -- & -- & $\checkmark$ & $\checkmark$ & -- & -- \\
\hline
\end{tabular}

SA: Situation Analysis, developed by Population Council

QIQ: Quick Investigation of Quality, MEASURE Evaluation

SARA: Service Availability and Readiness Assessment, World Health Organization

DHS-SPA: Demographic and Health Survey - Service Provision Assessment

MLE: Measurement, Learning \& Evaluation Project, UNC-Chapel Hill

PMA 2020: Performance Monitoring and Accountability 2020

IIPS: International Institute for Population Sciences 


\section{APPENDIX 4: TABLE 4 Questions and computable indicators of quality from from individual women in exit interviews and cross-sectional surveys}

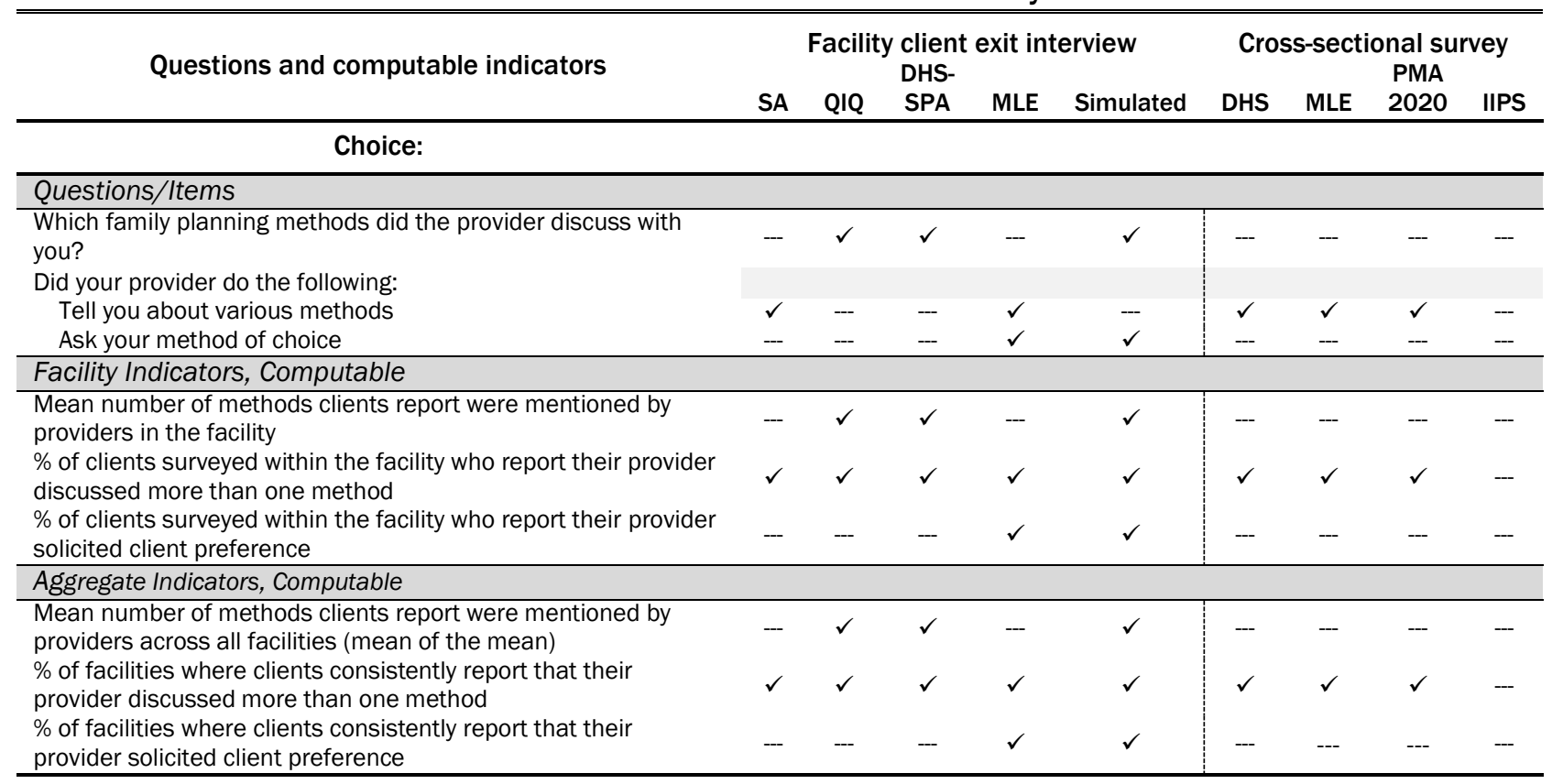

\section{Information:}

\section{Questions/Items}

Did your provider do the following:

Help you in selecting the method

Explain you how to use the selected method

Mention possible side effects of the chosen method

Discuss what to do in case of a method-related problem

Facility Indicators, Computable

$\%$ of clients surveyed within the facility who report their provider helped them select a method

$\%$ of clients surveyed within the facility who report their provider explained how to use the selected method

$\%$ of clients surveyed within the facility who report their provider mentioned possible side effects of the chosen method

$\%$ of clients surveyed within the facility who report their provider discussed what to do in case of a method-related problem

Aggregate Indicators, Computable

$\%$ of facilities in which clients consistently report their provider helped them select a method

$\%$ of facilities in which clients consistently report their provider explained how to use the selected method

$\%$ of facilities in which clients consistently report their provider mentioned possible side effects of the chosen method

$\%$ of facilities in which clients consistently report their provider discussed what to do in case of a method-related problem 
Table 4, Continued

\section{Questions and computable indicators}

\begin{tabular}{|c|c|c|c|c|c|c|c|c|}
\hline & \multicolumn{4}{|c|}{ Cross-sectional survey } \\
\hline & & DH & & & & & PMA & \\
\hline & QIQ & SPA & MLE & Simulated & DHS & MLE & 2020 & IIP \\
\hline
\end{tabular}

\section{Client and provider relations:}

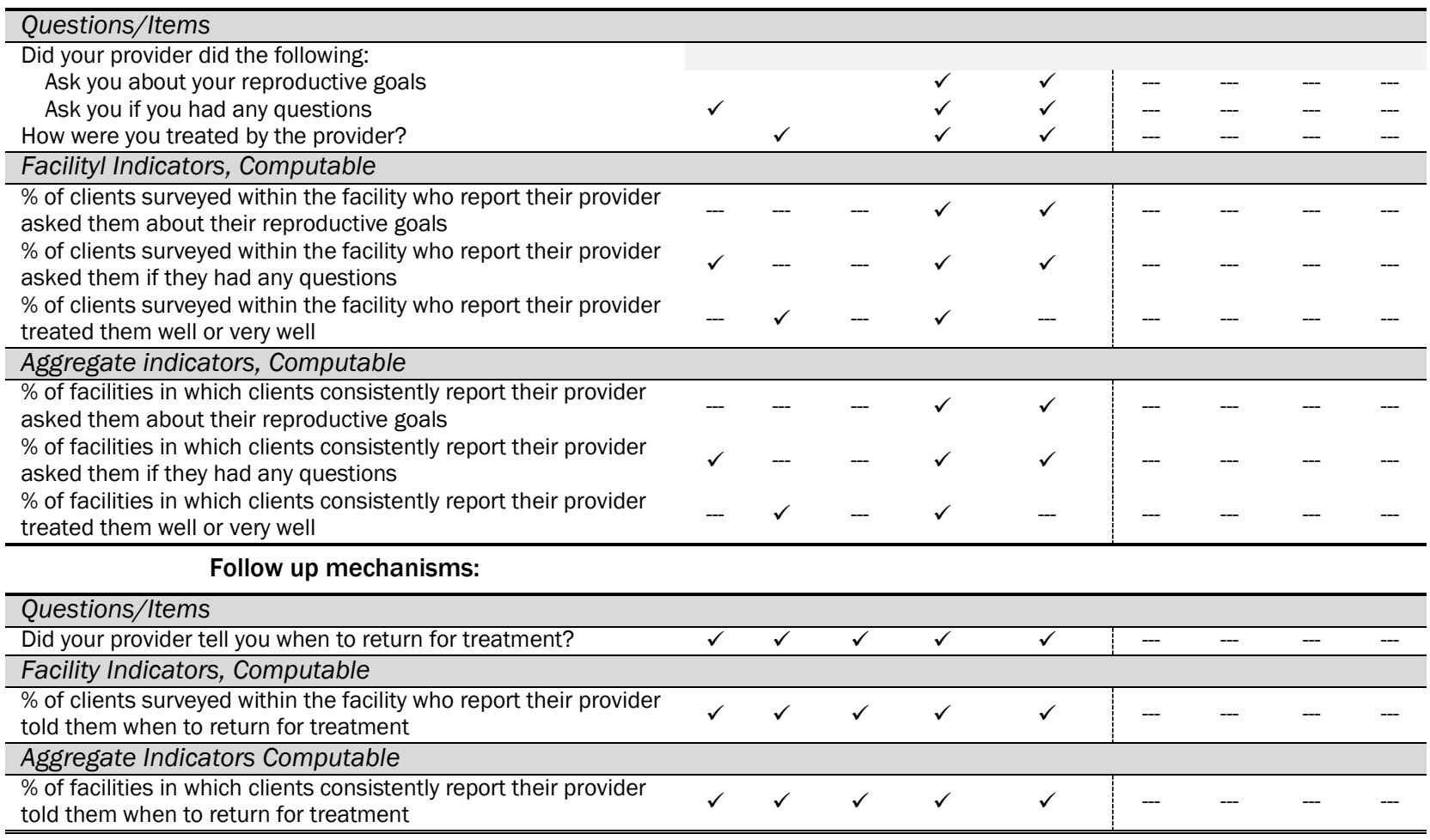

SA: Situation Analysis

QIQ: Quick Investigation of Quality

SARA: Service Availability and Readiness Assessment

DHS-SPA: Demographic and Health Survey - Service Provision Assessment

MLE: Measurement, Learning \& Evaluation Project

PMA 2020: Performance Monitoring and Accountability 2020

Simulated: Simulated clients, also known as "mystery clients" 


\section{References}

1. Bongaarts, J. 2011. Can family planning programs reduce high desired family size in sub-saharan Africa? International Perspectives on Sexual and Reproductive Health 37(4): 209-216.

2. Cleland, J. et al. 2006. Family planning: the unfinished agenda. Lancet 368(9549): 1810-1827.

3. Population Reference Bureau. 2013. Family Planning Worldwide 2013 Datasheet. www.prb.org/pdf13/family-planning-2013-datasheet eng.pdf.

4. Barry, T.M. 1996. Quality of care: from concept to action. A way ahead for sub-Saharan Africa FP and RH programmes. Afr J Fertil Sexual Reprod Heal 1(2): 85-91.

5. Bertrand, J. et al. 1995. Access, quality of care and medical barriers in family planning programs. Int Fam Plan Perspect 21: 64-69, 74.

6. Bruce, J. 1994. Quality of care: A brief history and a look ahead. Plan Parent Chall 2: 2-5.

7. Jain, A.K. 1989. Fertility reduction and the quality of family planning services. Studies in Family Planning 20(1): 1-16.

8. RamaRao, S. and R. Mohanam. 2003. The quality of family planning programs: Concepts, measurements, interventions, and effects. Studies in Family Planning 34(4): 227-248.

9. Bruce, J. 1990. Fundamental elements of the quality of care: a simple framework. Studies in Family Planning 21(2): 61-91.

10. Hull, V. 1996. Improving quality of care: a status report. Family planning. Popul Briefs 2(3): 6.

11. Mensch, B. et al. 1994. Family Planning in Nairobi: A Situation Analysis of the City Commission Clinics. International Family Planning Perspectives 20: 48-54.

12. Jain, A. et al. 1992. Quality of services, programme efforts and fertility reduction. Family Planning Programmes and Fertility. Eds. J.F. Phillips and J.A. Ross. Oxford: Clarendon Press. Pg. 202-221.

13. Ali, M. and J. Cleland. 1999. Determinants of contraceptive discontinuation in six developing countries. $J$ Biosoc Sci 31(3): 343-360.

14. Burke, H.M. and C. Ambasa-Shisanya. 2011. Qualitative study of reasons for discontinuation of injectable contraceptives among users and salient reference groups in Kenya. Afr J Reprod Health 15(2): 67-78.

15. Cotten, N. et al. 1992. Early discontinuation of contraceptive use in Niger and the Gambia. Int Fam Plan Perspect 18(4): 145-149.

16. Curtis, S.L. et al. 1997. Determinants of contraceptive failure switching and discontinuation: an analysis of DHS contraceptive histories. China Population Today 14(6): 7.

17. Mohanan, M. et al. 2015. The Know-Do Gap in Quality of Health Care for Childhood Diarrhea and Pneumonia in Rural India. Journal of the American Medical Association.

18. Greene, E. and J. Stanback. 2011. Old barriers need not apply: opening doors for new contraceptives in the developing world. Contraception 85(1): 11-14.

19. Tumlinson, K. et al. 2010. Measuring the usefulness of family planning job aids following distribution at training workshops. J Biosoc Sci 42(5): 695-698.

20. World Health Organization. 2004. Selected Practice Recommendations for Contraceptive Use. 
21. FHI360. 2012. Pregnancy Checklist. www.fhi360.org/NR/rdonlyres/eg7priv4amrttz2ejss2dds5qzjdhhf3wtq6e3waqemin3itekw7mwm6h7 3yfugw5vl7qimnmpqszh/PregnancyChecklistenrh1.pdf.

22. Abuya, T. et al. 2015. The effect of a multi-component intervention on disrespect and abuse during childbirth in Kenya. BMC Pregnancy Childbirth 15: 224.

23. Freedman, L.P. and M.E. Kruk. 2014. Disrespect and abuse of women in childbirth: challenging the global quality and accountability agendas. Lancet 384(9948): e42-44.

24. Van Lerberghe, W. et al. 2014. Country experience with strengthening of health systems and deployment of midwives in countries with high maternal mortality. Lancet 384(9949): 1215-1225.

25. World Health Organization. 2015. The prevention and elimination of disrespect and abuse during facilitybased childbirth. www.who.int/reproductivehealth/topics/maternal_perinatal/statement-childbirth/en.

26. Mohanan, M. et al. 2014. Effect of Chiranjeevi Yojana on institutional deliveries and neonatal and maternal outcomes in Gujarat, India: a difference-in-differences analysis. Bull World Health Organ 92(3): 187-194.

27. Kohler, J.C. 2011. Fighting Corruption in the Health Sector, Methods, Tools and Good Practices, United Nations Development Programme, Editor. New York. 76.

28. Amnesty International. 2010. Pregnant women in Burkina Faso dying because of discrimination. www.amnesty.org/en/news-and-updates/report/pregnant-women-burkina-faso-dying-becausediscrimination-20100127.

29. Tumlinson, K. et al. 2013. Simulated clients reveal factors that may limit contraceptive use in Kisumu, Kenya. Global Health: Science and Practice 1(3): 407-416.

30. Blanc, A.K., S.L. Curtis, T.N. Croft. 2002. Monitoring contraceptive continuation: links to fertility outcomes and quality of care. Studies in Family Planning 33(2): 127-140.

31. Huber, D. and E. Bowles. 1999. Family Planning and the Prevention of Abortion. www.reproline.jhu.edu/english/2mnh/2pa/pac proc/huber1.htm.

32. Tuoane, M., N.J. Madise, I. Diamond. 2004. Provision of family planning services in Lesotho. International Family Planning Perspectives 30(2): 77-86.

33. Huezo, C. and S. Diaz. 1993. Quality of care in family planning: clients' rights and providers' needs. Advances in Contraception 9(2): 129-39.

34. Askew, I., B. Mensch, and A. Adewuyi. 1994. Indicators for measuring the quality of family planning services in Nigeria. Studies in Family Planning 25(5): 268-283.

35. Brown, L. et al. 1995. Quality of care in family planning services in Morocco. Studies in Family Planning 26(3): 154-168.

36. Jain, A.K., J. Bruce, B. Mensch. 1992. Setting standards of quality in family planning programs. Studies in Family Planning 23(6,1): 392-395.

37. Ketting, E. 1994. Quality of care: an overview of major issues. Plan Parent Chall 2: 28-30.

38. Cohen, S.A. and C.L. Richards. 1994. The Cairo consensus: population, development and women. Fam Plann Perspect 26(6): 272-277.

39. Donabedian, A. 1988. The Quality of Care How Can It Be Assessed? JAMA 260(12): 1743-1748.

40. Simmons, R. and C. Elias. 1994. The study of client-provider interactions: A review of methodological issues. Studies in Family Planning 25(1): 1-17.

41. Fisher A. et al. 1992. Guidelines and Instruments for a Family Planning Situation Analysis Study. 
42. Miller, R.A. et al. 1991. The Situation Analysis Study of the family planning program in Kenya. Studies in Family Planning 22(3): 131-143.

43. Paine, K., M. Thorogood, K. Wellings. 2000. The impact of the quality of family planning services on safe and effective contraceptive use: A systematic literature review. Hum Fertil (Camb) 3(3): 186-193.

44. Fisher, A. et al. 1992. Guidelines and Instruments for a Family Planning Situation Analysis Study.

45. MEASURE DHS. 2012. www.measuredhs.com.

46. International Union for the Scientific Study of Population. 2009. The Demographic and Health Surveys (DHS) Project Past, Present and Future. http://iussp2009.princeton.edu/papers/93520.

47. MEASURE Evaluation. 2001. Quick Investigation of Quality (QIQ): A User's Guide for Monitoring Quality of Care in Family Planning. MEASURE Evaluation Manual Series 2. Chapel Hill: Carolina Population Center, University of North Carolina.

48. Bessinger, R.E. and J.T. Bertrand. 2001. Monitoring Quality of Care in Family Planning Programs: A Comparison of Observations and Client Exit Interviews. Int Fam Plan Perspect 27(2): 63-70.

49. Skiles, M.P. et al. 2013. Geographically linking population and facility surveys: Methodological considerations. Popul Health Metr 11(1): 14.

50. Burgert, C.R. and D. Prosnitz. 2014. Linking DHS Household and SPA Facility Surveys: Data Considerations and Geospatial Methods. DHS Spatial Analysis Reports 10. Rockville, MD: ICF International.

51. Whittaker, M. et al. 1996. Evaluating rural Bangladeshi women's perspectives of quality in family planning services. Health Care Women Int 17(5): 393-411.

52. Mensch, B. et al. 1994. Using situation analysis data to assess the functioning of family planning clinics in Nigeria, Tanzania, and Zimbabwe. Studies in Family Planning 25(1): 18-31.

53. Agha, S., A. Balal, F. Ogojo-Okello. 2004. The impact of a microfinance program on client perceptions of the quality of care provided by private sector midwives in Uganda. Health Serv Res 39(6,2): 2081-2100.

54. Al-Qutob, R. and L.S. Nasir. 2008. Provider perceptions of reproductive health service quality in jordanian public community health centers. Health Care Women Int 29(5): 539-550.

55. Bender, D.E. et al. 2008. Perceptions of quality of reproductive care services in Bolivia: Use of photo prompts and surveys as an impetus for change. Health Care Women Int 29(5): 484-506.

56. Koenig, M.A., M.B. Hossain, M. Whittaker. 1997. The influence of quality of care upon contraceptive use in rural Bangladesh. Studies in Family Planning 28(4): 278-289.

57. Mohammad-Alizadeh, S. et al. 2009. Women's perceptions of quality of family planning services in Tabriz, Iran. Reprod Health Matters 17(33): 171-180.

58. Mroz, T.A. et al. 1999. Quality, accessibility, and contraceptive use in rural Tanzania. Demography 36(1): 23-40.

59. Nakhaee, N. and A.R. Mirahmadizadeh. 2005. Iranian women's perceptions of family-planning services quality: A client-satisfaction survey. Eur J Contracept Reprod Health Care 10(3): 192-198.

60. Speizer, I.S. and K.A. Bollen. 2000. How well do perceptions of family planning service quality correspond to objective measures? Evidence from Tanzania. Studies in Family Planning 31(2): 163177.

61. Tu, X. et al. 2004. Do family-planning workers in China support provision of sexual and reproductive health services to unmarried young people? Bull World Health Organ 82(4): 274-280.

62. Hardee, K. et al. 2001. Quality of care in family planning clinics in Jamaica. Do clients and providers agree? West Indian Med J 50(4): 322-327. 
63. Huntington, D. and S.R. Schuler. 1993. The simulated client method: Evaluating client-provider interactions in family planning clinics. Studies in Family Planning 24(3): 187-193.

64. Leon, F.R. et al. 2007. Challenging the courtesy bias interpretation of favorable clients' perceptions of family planning delivery. Eval Rev 31(1): 24-42.

65. Madden, J.M. et al. 1997. Undercover careseekers: Simulated clients in the study of health provider behavior in developing countries. Soc Sci Med 45(10): 1465-1482.

66. Maynard-Tucker, G. 1994. Indigenous perceptions and quality of care of family planning services in Haiti. Health Policy Plan 9(3): 306-317.

67. Naik, S., T. Suchi, R. Lundgren. 2010. Options for maintaining quality family planning counseling: Strategies for refresher training. Int J Qual Health Care 22(2): 145-150.

68. Population Council. 1992. Quantitative assessment of the quality of care: Effects of provider training. INOPAL Updates. New York: Population Council.

69. Schuler, S.R. et al. 1985. Barriers to Effective Family Planning in Nepal. Studies in Family Planning 16(5): 260-270.

70. Mensch, B., M. Arends-Kuenning, A.K. Jain. 1996. The impact of the quality of family planning services on contraceptive use in Peru. Studies in Family Planning 27(2): 59-75.

71. Boyce, C. and P. Neale. 2006. Using mystery client: A guide to using mystery clients for evaluation input. Pathfinder International Tool Series Monitoring and Evaluation 3. Watertown, MA: Pathfinder International.

72. Leon, F.R., G. Quiroz, A. Brazzoduro. 1994. The reliability of simulated clients' quality-of-care ratings. Studies in Family Planning 25(3): 184-190.

73. Huntington, D., K. Miller, B. Mensch. 1996. The reliability of the situation analysis observation guide. Studies in Family Planning 27(5): 277-282.

74. Tumlinson, K. et al. 2014. Accuracy of Standard Measures of Family Planning Service Quality: Findings from the Simulated Client Method. Studies in Family Planning 45(4).

75. Do, M.P. and M.A. Koenig. 2007. Effect of family planning services on modern contraceptive method continuation in Vietnam. J Biosoc Sci 39(2): 201-220.

76. Gubhaju, B. 2009. Barriers to sustained use of contraception in Nepal: Quality of care, socioeconomic status, and method-related factors. Biodemography and Social Biology 55(1): 52-70.

77. Hong, R., L. Montana, V. Mishra. 2006. Family planning services quality as a determinant of use of IUD in Egypt. BMC Health Services Research 6: 79-87.

78. Sanogo, D. et al. 2003. Improving quality of care and use of contraceptives in Senegal. Afr J Reprod Health 7(2): 57-73.

79. RamaRao, S. et al. 2003. The link between quality of care and contraceptive use. International Family Planning Perspectives 29(2): 76-83.

80. Mwaikambo, L. et al. 2011. What Works in Family Planning Interventions: A Systematic Review. Studies in Family Planning 42(2): 67-82. 
